\title{
Induction plasma synthesis of ultrafine SiC
}

\author{
François Gitzhofer \\ Plasma Technology Research Center (CRTP), Department of Chemical Engineering \\ University of Sherbrooke, Québec, J1K 2R1, CANADA.
}

\begin{abstract}
Induction plasma synthesis of ultrafine powders has been studied using different precursors, different plasma torch configurations and injection conditions. The long residence time available in the r.f. plasma, as well as the high temperature are necessary conditions for decomposition in the vapor phase of the injected species. High cooling rates of the plasma gas in the condensation region of the reactor guarantees homogeneous nucleation of $\mathrm{SiC}$ or doped $\mathrm{SiC}$ with limited heterogeneous nucleation by the reactor wall. Heat and mass transfer in the r.f. induction plasma have been intensively studied both experimentally and theoretically with the developement of reliable numerical models. The synthesis of $\mathrm{SiC}$ in the induction plasma can benefit from these data to design the reactors. Many parametric studies have shown that it is possible to influence and maintain SiC UFP quality. Solid elemental Si as a starting material is a promising avenue for UFP SiC synthesis.
\end{abstract}

\section{INTRODUCTION}

The term "ultrafine powders" (UFP), also called nanosized powders, refers to particles sized between 5 and $100 \mathrm{~nm}$. The demand for advanced ceramic powders (including nanosized ceramic powders) in the U.S. market is increasing and will jump from $\$ 626$ million in 1993 to almost $\$ 1.1$ billion by 2000 , according to a study conducted by Business Communications Co. Inc., Norwalk, Connecticut. UFP are being developped for sintering applications as well as for the reinforcement of alloys. As there are many published review papers on ultrafine powders (1-5) and more specifically on thermal plasma UFP generation (6-8), this paper will focus on the $\mathrm{SiC}$ ultrafine powder synthesis process, using the inductively coupled plasma.

Ultrafine $\mathrm{SiC}$ powders have been prepared in recent years by various investigators and by various methods; e.g. in d.c. and r.f. plasma reactors, using $\mathrm{SiC}$ resistance element furnaces or by microwave, laser and CVD techniques. A range of starting materials can be and have been employed in these processes, including solids $\left(\mathrm{Si}, \mathrm{SiO}_{2}\right)$, liquids $\left(\mathrm{CH}_{3} \mathrm{SiCl}_{3}\right)$ and gases $\left(\mathrm{SiH}_{4}\right)$; methane being the principal carburizing agent used. The variety of combinations of these various $\mathrm{SiC}$ formation precursors that have been employed in the different synthesis techniques illustrates the various attempts made to improve some of the following process factors: $\mathrm{SiC}$ production rate, degree of conversion, powder quality (i.e. uniform nanoparticle size distribution) and sinterability. In the evolution of processes development leading to ultrafine powder synthesis, a need has always existed to increase the residence time for reactants in the plasma reactor, eg. by such techniques as the Liquid Injection Plasma Synthesis (LIPS) (9) in the case of the d.c. plasma or to obtain the benefit from the natural characteristics of the induction plasma (10). Induction plasma has therefore gained wide acceptance for the synthesis of $\mathrm{SiC}$ by process researchers all around the world. Its unique features (no contamination by electrodes, central axis reactants injection, long residence time in the plasma zone, no limitations in the plasma gas chemistry) are all very beneficial to those particular processes that involve the use of low cost, solid precursors. The most widely adopted and typical application for $\mathrm{SiC}$ ultrafine powders is the preparation of sintered thermomechanical parts, thus the incorporation of sintering aids such as Boron have been found to be necessary. The technique of induction plasma synthesis for Boron doped $\mathrm{SiC}$ has been developped and adapted for the introduction of the required Boron as $\mathrm{BCl}_{3}$ during the $\mathrm{SiC}$ vapour phase synthesis. The qualities of powders produced by this process route will be discussed later as a function of the sintering results for various r.f. plasma operating conditions. Silicon Carbide is a widely used material for wear and corrosion resistance, in chemicals pumping and heat exchangers [Sheshadri (11)] as well as potential applications in diesel engines. Apart from producing sintered parts, applications for $\mathrm{SiC}$ ultrafine powders are to be found in nanoreinforcement, through the introduction of a second phase of $\mathrm{SiC}$ into a matrix material. Mitsubishi Mining and Cement Co., Ltd., Japan have developped a $\mathrm{MgO} / \mathrm{SiC}$ composite. Potential benefits from the use of $\mathrm{SiC}$ nanoparticles could lie in the superplasticity forming process, already developped for zirconia by Lockheed Missiles \& Space Co. Depending on the actual ultrafine powder fabrication technique used, any contamination of UFP could be adverse for the eventual sintered products. 
The different routes to produce UFP were reviewed by Andrievski (2). He distinguishes physical methods that include gas-condensation in inert or reactive gas and high energy destruction by milling, from chemical UFP preparation by synthesis and thermal decomposition. Physical methods of UFP preparation have been extensively reviewed by Andrievski (2), Gleiter (12). More attention will be given here to the plasma routes. Vissokov et al. (3) published a review of the different plasmachemical technologies for UFP, which does not include SiC. One can however notice that the 5 stages identified by the author for the production of UFP using plasma technology are applicable to SiC: 1. Introduction and mixing of the reactants, 2. Heating/melting and vaporization of the solid phase, 3 . Chemical reactions in the gas phase, 4. Quenching which fixes the composition of the desired product, .5. Filtering of UFP by cyclones, mechanical or electro-filters.

\section{INDUCTION PLASMA UFP SIC SYNTHESIS}

\section{Gaseous reactants}

Due to its very high temperature and high energy density, as well as operating in various atmospheres, plasma techniques are widely recognized as among the most advanced technologies for SiC ultrafine powder production. Synthesis of $\mathrm{SiC}$ powders from the $\mathrm{SiH}_{4}+\mathrm{CH}_{4}$ system is thermodynamically favorable. The practical reaction temperature may be as low as $1200-1400^{\circ} \mathrm{C}$ [Kato et al.(13)]. Vogt et al. (14) prepared ultrafine $\mathrm{SiC}$ powder as a $\mathrm{B}$-SiC pure phase in a thermal argon r.f. plasma, using silane and methane as starting materials. The synthesized particles diameter ranged from 10 to $60 \mathrm{~nm}$, with a specific surface area of 60 to $130 \mathrm{~m}^{2} / \mathrm{g}$ but due to extensive agglomeration, the apparent particle size was greater than $0.1 \mu \mathrm{m}$. Axial injection of the reactants gave a limited degree of particle size control in the SiC synthesis. By increasing the depth of reactants penetration into the tail flame, the surface area of the powder was increased, reflecting a reduction in the mean particle size. Variations in plate power, reactant feed rates, and the quench gas properties could also affect the powder surface area and mean particle size. Kijima et al. (15) used a $15 \mathrm{~kW}$ induction plasma to synthetize B-SiC UFP with an estimated $6 \mathrm{~nm}$ particle diameter. Suzuki et al. (16) prepared $\mathrm{SiC}_{-} \mathrm{Si}_{3} \mathrm{~N}_{4}$ composite fine powders from chlorosilanes by r.f. thermal plasma. Fig. 1 shows the r.f. plasma torch used. The $\mathrm{SiC}_{-} \mathrm{Si}_{3} \mathrm{~N}_{4}$ composite fine powders were prepared by injecting chlorosilanes $\left(\mathrm{SiCl}_{4}, \mathrm{SiHCl}_{3}, \mathrm{SiH}_{2} \mathrm{Cl}_{2}\right), \mathrm{C}_{2} \mathrm{H}_{4}$ and $\mathrm{NH}_{3}$ to the tail flame of r.f. plasma. Generally, the powders obtained were composed of $\mathrm{Si}, \mathrm{SiC}, \mathrm{Si}_{3} \mathrm{~N}_{4}, \mathrm{C}$ and amorphous particles.

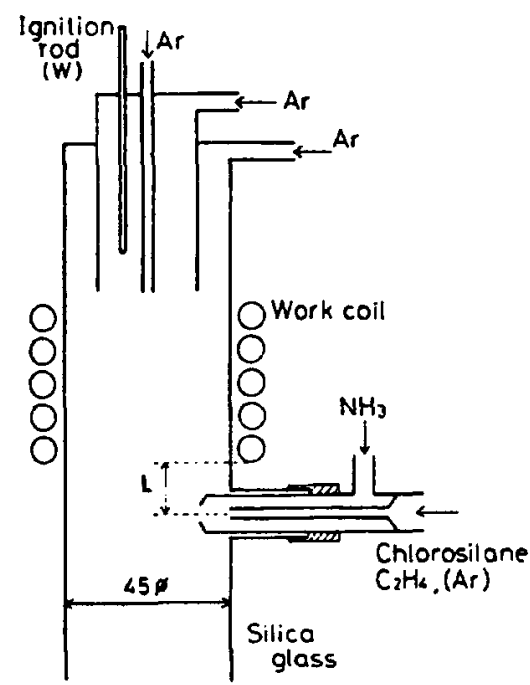

Fig. 1 r.f. plasma torch for $\mathrm{SiC}_{-} \mathrm{Si}_{3} \mathrm{~N}_{4}$ composite UFP [Suzuki et al. (16)]

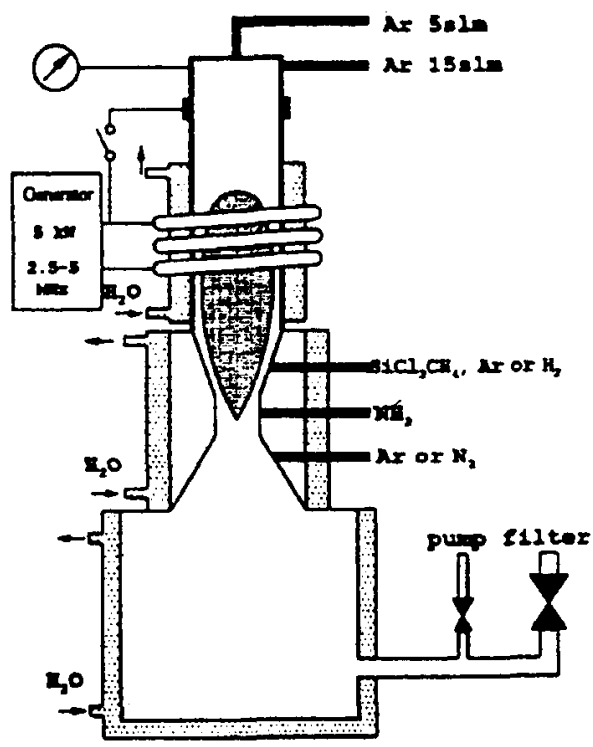

Fig.2 Reactor design for $\mathrm{Si}_{3} \mathrm{~N}_{4} \mathrm{SiC}$ composite UFP [Mach et al. (17)]

The surface area of the powder was from 46 to $100 \mathrm{~m}^{2} / \mathrm{g}$ and the particle size was from 20 to $200 \mathrm{~nm}$. $\mathrm{SiO}_{2}$ was detectable in the powder by XPS. It was found that after heat treatment at $1773 \mathrm{~K}$ for $1 \mathrm{~h}$ in $\mathrm{Ar}$, the amorphous phase disappeared and the remaining crystalline phases in the powder were $\mathrm{SiC}$ and $\mathrm{Si}_{3} \mathrm{~N}_{4}$. The by-product, $\mathrm{NH}_{4} \mathrm{Cl}$, of this process was removed by heating in flowing $\mathrm{Ar}$ at $623 \mathrm{~K}$ for $1 \mathrm{~h}$. Mach et al. (17) synthesized $\mathrm{Si}_{3} \mathrm{~N}_{4}-\mathrm{SiC}$ composite powders with an Ar RF induction plasma from $\mathrm{SiCl}_{4}$ and $\mathrm{SiCl}_{3} \mathrm{CH}_{4}$ respectively and $\mathrm{NH}_{3}$. The reactor design is shown in Fig. 2. The overall particule size distribution is in the range 5-80 nm. Praegraphitic structures decrease with the increase of ammonia flow and or quenching rate. With excess of ammonia, only amorphous powders are produced. Inukai (18) introduced methyl-trichlorosilane diluted with Argon in a $4 \mathrm{~kW}$ induction plasma. The 20-50 nm diameter B SiC powders are associated with traces of $\alpha-\mathrm{SiC}$ as well as with free silicon and were collected on the reactor wall. Mitsui and Kato (19) prepared beta silicon carbide powder from the $\mathrm{SiCl}_{4}-\mathrm{CH}_{4}-\mathrm{H}_{2}$ system 
using RF-plasma. They studied the effect of reaction conditions on the chemical composition and particle size of the powders. Under the condition of $\left[\mathrm{SiCl}_{4}\right]=0.1 \mathrm{vol} \%$ and $\left[\mathrm{CH}_{4}\right]=0.13 \mathrm{vol} \%$, the $\mathrm{C} / \mathrm{Si}$ ratio of the powders increased sharply with decreasing $\left[\mathrm{H}_{2}\right]$. The $\mathrm{C} / \mathrm{Si}$ ratio increased moderately with increase of $\mathrm{CH}_{4}$, and thus the $\mathrm{C} / \mathrm{Si}$ ratio could be easily controlled by the flow rate of $\mathrm{CH}_{4}$. The crystallite size of the $\mathrm{SiC}$ powders had a tendency to increase with increasing reaction temperature. This may be due to a decrease in the supersaturation ratio at higher temperatures.

\section{Induction plasma technology evolution}

As extensive use of r.f. plasma has developed in the production of ultrafine powders of various materials, much effort has been also made to improve the r.f. plasma system itself. Hollabaugh et al. (20) developed a high-temperature plasma tube that overcomes the meltdown problem of the water and gas-cooled quartz plasma tubes most commonly used. The r.f. plasma system consists of the plasma tube and its associated power generator, a reaction and cooling off chamber, a powder collection system, and a gas-flow control and vacuum system, as shown in Fig. 3. The key feature of this system is the placement of several heavywalled, water-cooled copper fingers inside a quartz mantle to shield the mantle from the intense radiation of the plasma. These copper fingers not only keep the quartz mantle cool but also transmit, through the induced voltage and current, energy from the primary r.f. coil to the plasma. Ultrafine silicon carbide powder was made by radial injection of silane, methane, and hydrogen into the tail flame of the plasma. The composition of the silicon carbide powder could be varied over a wide range from excess silicon to excess carbon. This was accomplished by adjustments in the feed gas composition and/or the r.f. power. Particle size of the powder, as determined by TEM and BET surface area measurements, was 10 to $20 \mathrm{~nm}$, with a specific area of $100 \mathrm{~m}^{2} / \mathrm{g}$ and some chainlike agglomerates were observed. Kameyama et al. (21) also prepared $\mathrm{B}-\mathrm{SiC}$ using a dual r.f. plasma torch system. This new radio-frequency (r.f.) thermal plasma system overcomes both the low power efficiency and the unstable induction plasma commonly used. The injection of methane and $\mathrm{SiH}_{4}$ was stoichiometric. High purity $\mathrm{SiC}$ was produced The reaction mechanisms as explained by Kameyama are: $\mathrm{Si}+\mathrm{SiC}_{2} \rightarrow-2 \mathrm{SiC}$ in the periphery and $\mathrm{Si}+\mathrm{C}-->\mathrm{SiC}$ in the central high temperature zones.

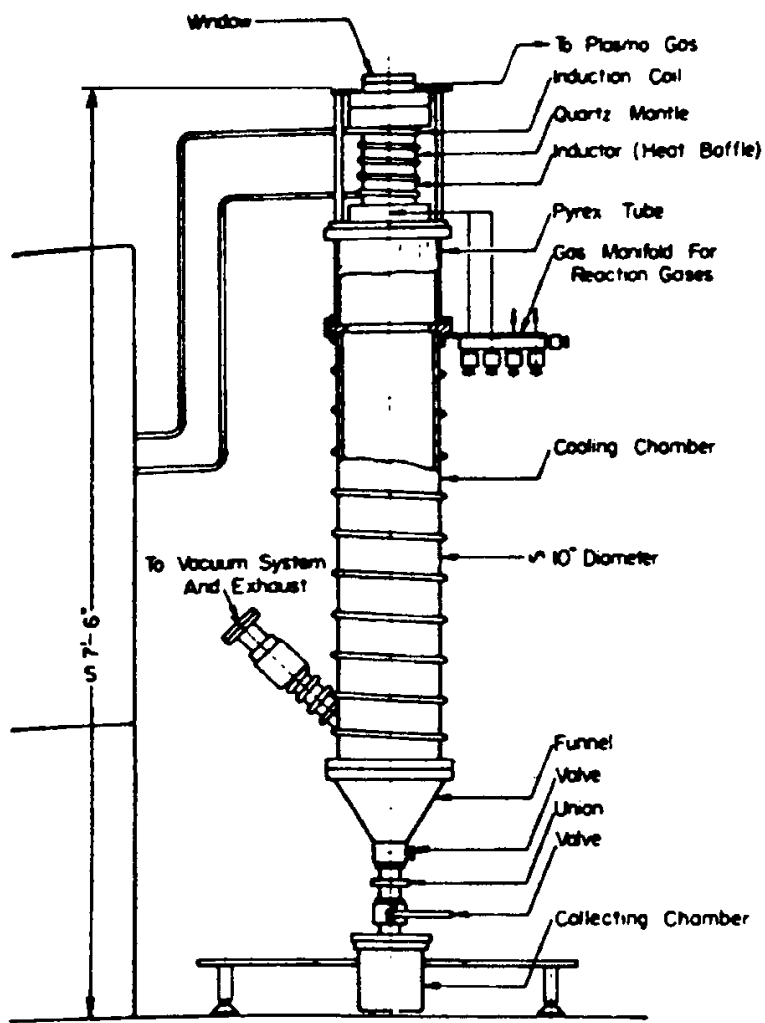

Fig.3 Induction plasma UFP reactor

[Hollabaugh et al. (20)]
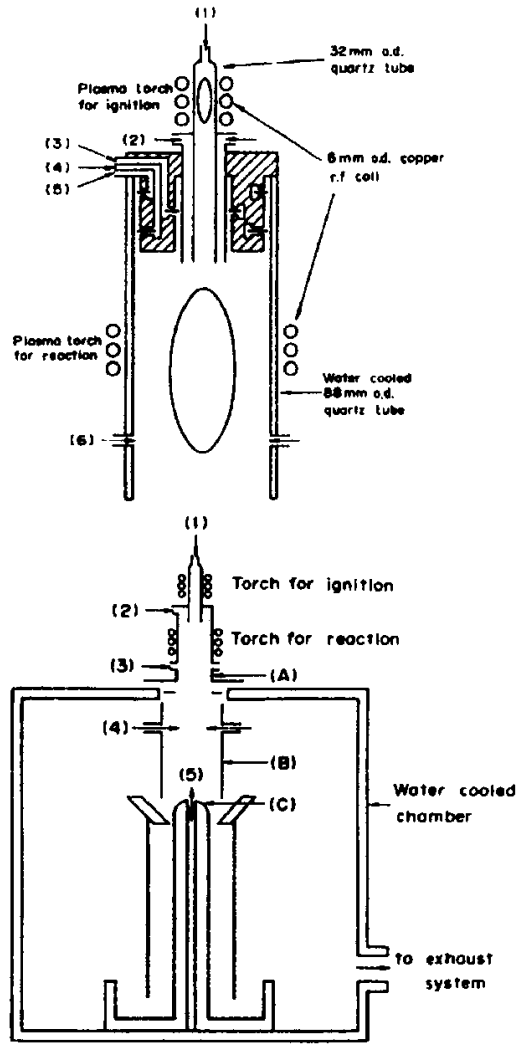

Fig.4 Dual r.f. torch system

[Kameyama et al.(21)]

The key features of this system are the application of all solid state type r.f. power supply units and the superposition of a small ignitor $(0,7 \mathrm{~kW})$ r.f. - plasma onto the main r.f. - plasma. High power efficiency (over $75 \%$ ) was obtained with the all solid state type r.f. power supply units of $30 \mathrm{~kW}$ at $3 \mathrm{MHz}$. Mixed reactant gases of $\mathrm{CH}_{4}$ and $\mathrm{SiH}_{4}$ are introduced into the upper part of the main plasma flame from port [2] with the argon carrier gas, as shown in Fig. 4. Powders formed were deposited on the following three 
places: the wall of the plasma torch [A], a collector quartz tube [B] and a copper cylinder [C] cooled with water. Quenching gases following reaction are also able to be fed in from ports [3], [4] and [5]. Small amounts of amorphous powders were deposited on the inner wall of the main plasma torch, i.e. at the place shown in Fig. 4 [A]. In the product amorphous phases, $\mathrm{SiC}, \mathrm{SiH}, \mathrm{CH}$ and $\mathrm{SiCH}_{3}$ species were detected by IR spectroscopy. On the other hand, powders collected at [B], and $[\mathrm{C}]$ in Fig. 4 were fully crystalline.

Yoshida et al. (22) developed the "hybrid" plasma concept which is characterized by the superposition of a radio-frequency piasma and a d.c. arc jet and applied it to synthesize SiC ultrafine powders. Lee et al. (23) synthesized ultrafine $\mathrm{Si}_{3} \mathrm{~N}_{4}$ and $\mathrm{Si}_{3} \mathrm{~N}_{4}+\mathrm{SiC}$ mixed powders through the thermal plasma, chemical vapor deposition (CVD) using a hybrid plasma, as shown in Fig. 5. The reactant, $\mathrm{SiCl}_{4}$, was injected into the arc jet and completely decomposed in the hybrid plasma, the second reactant, $\mathrm{CH}_{4}$ and /or $\mathrm{NH}_{3}$, being injected into the tail flame through multistage ring slits. For the preparation of $\mathrm{Si}_{3} \mathrm{~N}_{4}+\mathrm{SiC}$ mixed powders, the N/C composition ratio and particle size could be controlled not only by regulating the flow rates of the $\mathrm{NH}_{3}$ and $\mathrm{CH}_{4}$ reactant gases and the quenching gas, but also by adjusting the reaction volume. The results of this study provide sufficient evidence to suggest that multistage injection is very effective for regulating the condensation process of fine particles in a plasma tail flame.

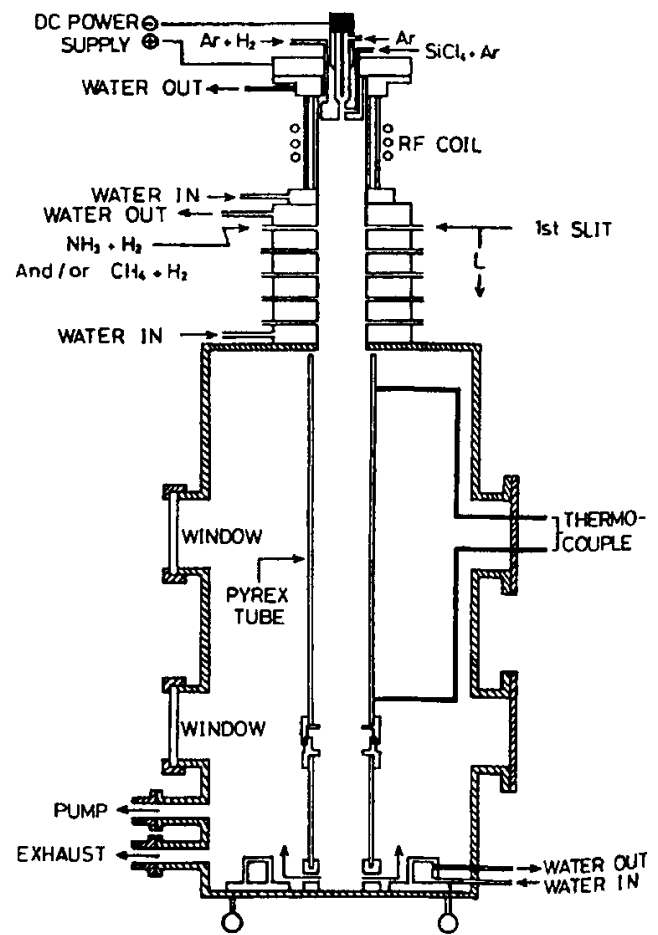

Fig.5 Hybrid plasma system [Lee et al. (23)] plasma

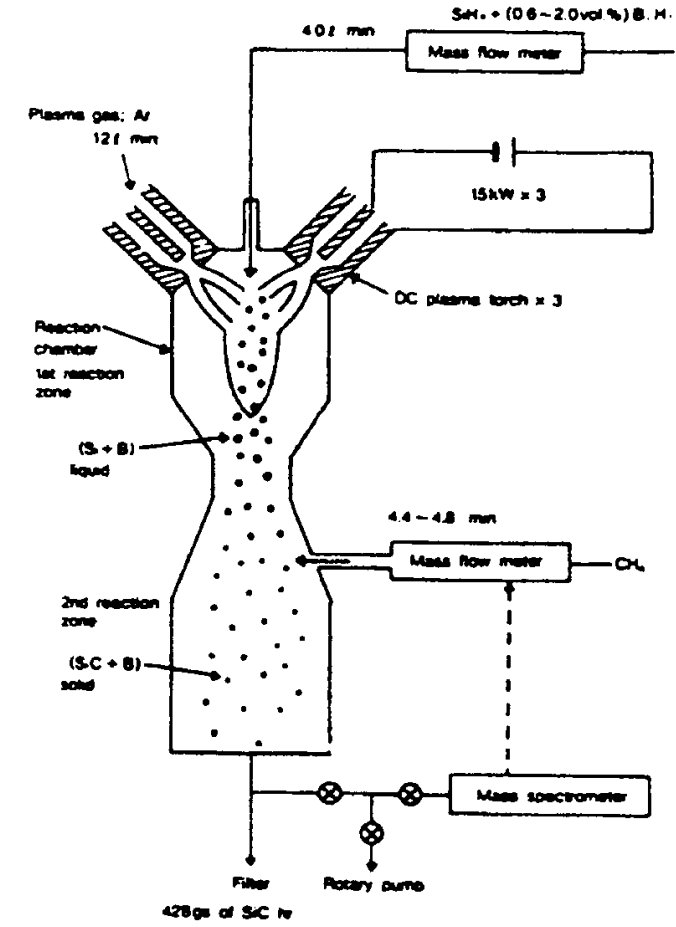

Fig.6 Schematic of the triple convergent d.c. [Kondo and Saiki (33)]

\section{Solid SiC precursors}

The use of solid starting materials for $\mathrm{SiC}$ powder preparation by plasma includes: $\mathrm{CH}_{4}$ and $\mathrm{SiO}_{2}$ in an r.f. induction-produced plasma [British Titan Products $\mathrm{Co} .(24)], \mathrm{SiO}_{2}$ and carbon in a consumable electrode [Kuhn, (25)], Metallic Si and $\mathrm{CH}_{4}$ in a transferred arc plasma [Ando et al., (26)]. Kong et al. $(27,28)$ described the production of silicon carbide in an argon plasma jet reactor (confined jet) operated at power levels of $22 \mathrm{~kW}$. Either $\mathrm{SiO}_{2}$ powder $(44 \mu \mathrm{m}$ in size) or laboratory produced $\mathrm{SiO}$ was used as the starting material, with methane serving both as the carrier gas and as the reductant. Some other plasma systems have also been used with solid precursors of $\mathrm{SiO}_{2}$ or Si: Inoue et al. (29); Nariki et al. (30); Tanaka et al. (31).

Synthesis of UF SiC has been performed by Stachowicz et al. (32) with "rice hulls" used as the raw material. Rice hulls contain finely distributed silica and active carbon which acts as a $\mathrm{C}$ source for $\mathrm{SiC}$ formation. Unreacted silica and excess of carbon was found to be present in the B-SiC powder. The various reactions which occur at high temperature between $\mathrm{SiO}_{2}$ and $\mathrm{C}$ are also discussed in this paper. 10 to $20 \mathrm{~nm}$ UFP were produced with a $20 \mathrm{~kW}$ r.f.reactor. Powder post treatment consisted of carbon removal by oxidation in air followed by silica removal by HF leaching.

In recent years, a number of studies have been performed to synthesize boron-doped SiC ultrafine powders under plasma conditions. Improvements of the SiC UFP synthesis process should lead to lower sintering temperatures, higher densities with smaller and more uniformly distributed grains, as well as few if any uniformly distributed micropores. Kondo and Saiki (33) developed a two-step process for 
synthesizing boron-doped $\mathrm{SiC}$ powders using the arc plasma method. In this process, the reaction chamber was divided into two reaction zones, in which the reaction conditions were independent of each other. Powders were synthesized in two steps: 1) nucleation and growth of the boron containing spherical molten silicon particles, and 2) carbonization of the molten silicon particles. Premixed gases of $\mathrm{SiH}_{4}+(0.6-2.0$ vol.\% $\mathrm{B}_{2} \mathrm{H}_{6}$ ) were supplied and injected into the conjunction of three d.c. plasma jets in the first reaction zone. Even though, this method does not involve induction plasma technology, the method used has some of the characteristics of r.f. plasma as seen from Fig. 6. It was proposed that the following phenomena take place in the reaction zone: the supplied gases enter the combined plasma jets to be thermally decomposed to vapors of silicon and boron, and spherical, molten silicon particles, containing uniformly distributed boron, nucleate and grow as the vapors of silicon and boron condense in the cooling plasma gases. Boron-doped $\mathrm{SiC}$ powders, with a size range of 0.3 to $0.5 \mu \mathrm{m}$, were synthesized from the molten silicon particles by injecting $\mathrm{CH}_{4}$ gas into the second reaction zone. The powders were collected in a bag filter behind the chamber. One of the reasons for dividing the synthesis process into two steps was proposed as follows: the injection of $\mathrm{CH}_{4}$ gas together with $\mathrm{SiH}_{4}+\mathrm{B}_{2} \mathrm{H}_{6}$ gases into the first reaction zone generates mixtures of $\mathrm{SiC}$, carbon and silicon particles. The amount of the $\mathrm{SiC}$ particles, however, was less than $90 \%$ of the product mixtures and the particle sizes were much finer. Another factor for consideration was that nucleation of silicon and boron might take place separately; particles of SiC and $\mathrm{B}_{4} \mathrm{C}$, for example, might subsequently develop separately, as a result. In such a case, the $\mathrm{SiC}$ powder with boron uniformly distributed in each particle would not be obtained. From this viewpoint, the objective guiding the preparation of inflight doped powders is the production of high purity, spherical or equiaxial powders, with uniform dispersions of additives in the SiC UFP and a narrow size distribution. Carbone and Rossing (34) and Baumgartner and Rossing (35) reported on the synthesis and pressureless sintering of B-doped $\mathrm{SiC}$ powders from the $\mathrm{SiCl}_{4}+\mathrm{CH}_{4}+\mathrm{BCl}_{3}$ and the $\mathrm{SiCl}_{4}+\mathrm{H}_{\mathrm{X}} \mathrm{C}_{\mathrm{y}} \mathrm{Cl}_{\mathrm{z}}+\mathrm{BCl}_{3}$ reaction systems, respectively, using d.c. plasma.

\section{HEAT AND MASS TRANSFER}

Plasma transport properties, as well as the momentum and heat transfer phenomena in plasma reactors, have been widely reported in the literature. However mass transfer has received little attention since the pionnering work of Dundas (36) and Barnes and Nikdel (37). Mixing studies are very important to obtain basic understanding of the species distribution and concentration in the plasma gases and recently, Rahmane et al. (38) and Soucy et al. $(39,40)$ have conducted several mixing studies on the induction plasma synthesis process by the injection of a tracer gas. The results have show that mass transfer is essentially achieved by molecular diffusion in the highest temperature regions whereas at lower temperatures, turbulence takes over and the mixing of the gases becomes very rapid. Cold gas injection has also been studied with radial as well as axial injection geometry as a function of the gas velocity and injector design.

\section{INDUCTIVELY COUPLED PLASMA SIC UFP SYNTHESIS AT THE CRTP}

\section{Historical review}

Laflamme (41) has considered various $\mathrm{SiC}$ reaction precursors $\left(\mathrm{SiO}_{2}, \mathrm{SiCl}_{4}, \mathrm{Si}\right)$ but his experimental work used elemental Si because a prior thermodynamic equilibrium and kinetic study showed that the silicon carburization is favored at temperatures higher than the melting point of Si Fig. 7, while the kinetic study, as presented in Fig. 8, shows that in less than $1 \mathrm{msec}$. at temperatures over $2400 \mathrm{~K}$, the carburization of the $\mathrm{Si}$ vapor is already complete. In order to increase the silicon vaporization rate, the reactor design evolved from a simple Si powder injection in the DC plasma to a rotating cylindrical reactor, with a liquid Si film trapped by centrifuged force and evaporated by the central plasma jet.

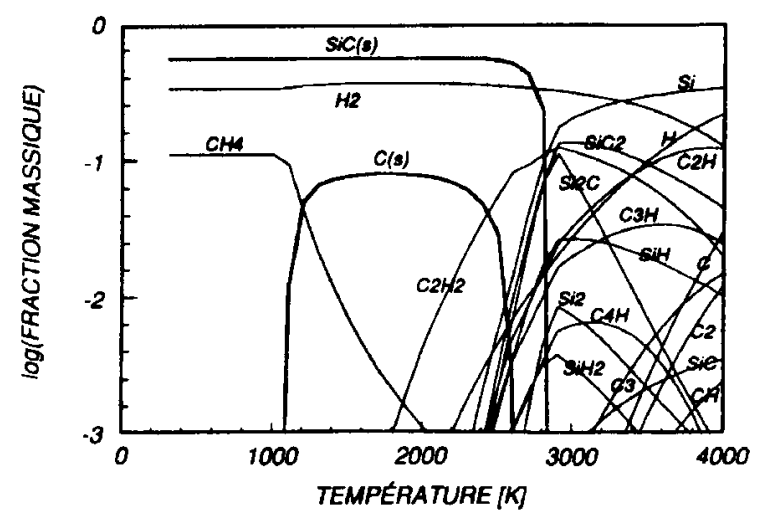

Fig. 7 Thermodynamic equilibrium of $\mathrm{Si}-\mathrm{C}-\mathrm{H}$ at 101.3kPa $\mathrm{CH}_{4} / \mathrm{Si}=1.5 ; \mathrm{H}_{2} / \mathrm{Si}=10$ ()

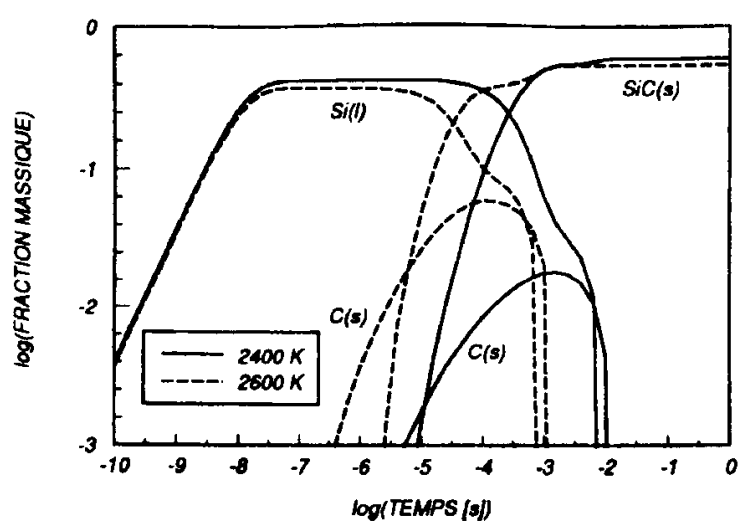

Fig. 8 Mass fraction as a function of time for $\mathrm{CH}_{4} / \mathrm{Si}=1$ id. Fig 7 after Laflamme(41) 
Guo (42) followed Laflamme's work with a dry powder collection method and a modified Laflamme rotating reactor. The UFP collected on the metallic filter had a particle size range from 16 to $30 \mathrm{~nm}$ with corresponding specific area of 60 to $120 \mathrm{~m}^{2} / \mathrm{g}$ from a $35 \mathrm{~kW}$ DC plasma. However, severe limitations of the vaporization rate to as little as from 1 to $3 \mathrm{~g} \mathrm{Si} / \mathrm{min}$ were encountered because of the formation of a dense Si vapor layer around the molten pool, limiting further heat transfer to the pool. Furthermore, the reproducibility and the control of the process was poor (free $\mathrm{Si}$ and free $\mathrm{C}$ accumulated in the $\mathrm{SiC}$ powder). The use of induction plasma technology with injected Si was then subsequently considered.

\section{Induction plasma synthesis of $\mathrm{SiC}$ research progress}

The simultaneous axial injection of $\mathrm{Si}$ and $\mathrm{CH}_{4}$, together with the long reactants residence time in the plasma zone and the large plasma volume are all desirable for the evaporation and reaction processes to proceed in the high temperature zone of the overall plasma volume. The experimental setup employed is presented in Fig. 9. Typical powders collected from the filter are shown in Fig. 10. The measured powder size range was from 40 to $80 \mathrm{~nm}$, with purities trending to $98 \% \mathrm{SiC}$. Powders collected from other system parts were found to be mixtures of $\mathrm{SiC}$, spheroidized silicon, unreacted free silicon and free carbon. By appropriate selection of the experimental parameters, a conversion of 91 to $92 \%$ was obtained, using $30 \mu \mathrm{m}$ mean particle size input $\mathrm{Si}$, at $50 \mathrm{~kW}$ plate power.

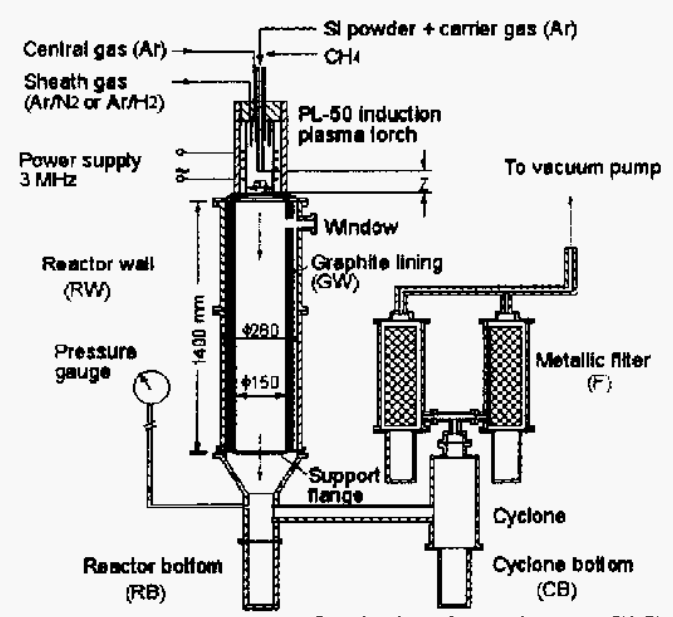

Fig. 9 Reactor set-up for induction plasma SiC UFP synthesis after Guo (42)

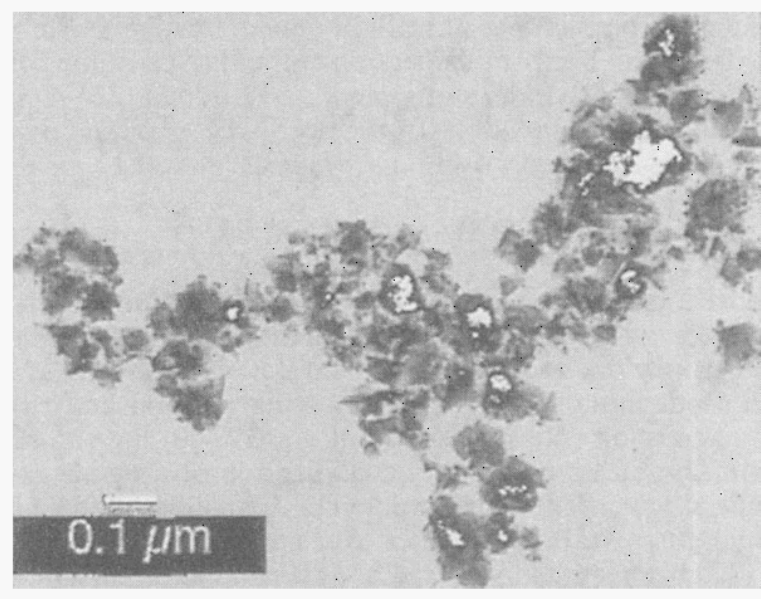

Fig. $10 \mathrm{SiC}$ UFP collected on the filter [F] Guo (42)

Reaction mechanisms proposed are based on gas phase reactions. Once the powder is injected, the melting of Si begins ( $\mathrm{Si}$ spheres are present on the reactor wall), but no reaction with the dissociated methane is taking place. The spheres do not show any detectable presence of $\mathrm{SiC}$ on their surface. Moreover, preliminary evaporation tests with $60 \mu \mathrm{m} \mathrm{Si}$ particles produced 30 to $40 \mathrm{wt} \%$ of evaporation. $\mathrm{CH}_{4}$ coinjected with the Si does not change this evaporation percentage. With smaller (30 $\mu \mathrm{m}$ diameter) Si starting powder, the evaporation percentage increased to $90 \%$. This increase is associated with the absence of SiC on the surface of the Si spheres and proves that the SiC formation is a gas phase process.

A parametric study has also been made by Guo (42) in which he demonstrates that the processing parameters such as the plasma power level, plasma gas composition, reactants injection probe position, feed rates of injected Si and the $\mathrm{C} / \mathrm{Si}$ molar ratio, significantly affect the conversion and the quality of the SiC powder obtained.

In-flight $\mathrm{SiC}$ Boron doped UFP has also been produced by Guo (42) using the same system as described previously and with $\mathrm{BCl}_{3}$ co-injection. The advantage of Boron in-flight doping has been well demonstrated by Guo, achieving an improvement of the sintering of SiC UFP compacts. However, these powders had sintering volume shrinkage as high as $24 \%$, with a $15 \%$ weight loss. The residual $\mathrm{Cl}$ content as well as the evaporation of volatile Boron oxide $\left(\mathrm{B}_{2} \mathrm{O}_{3}\right)$ are the principal reasons for these volume and mass changes.

\section{VAPOR PHASE UFP FORMATION}

The different techniques described previously which involve induction plasma UFP SiC synthesis are all gas phase reactions. Thermodynamic and kinetic aspects of the homogeneous nucleation of vapor condensation was extensively discussed by Mc Donald $(43,44)$. Homogeneous nucleation needs a high degree of supersaturation, with a large number of nuclei required to be created [Abraham (45) and Springer (46)]. Girshick et al. (47) have shown that in the condensation area of the plasma reactor, gas temperature can drop at rates of $10^{4} \mathrm{~K} / \mathrm{s}$, which makes the homogeneous nucleation the predominant mechanism. 
Kato (48) mentionned that the nucleation rate is very sensitive to the supersaturation ratio (SR). When SR increases from 4 to 5 , the nucleation rate increases from $10^{-10}$ to $10^{-0.7}$ with the following equation of formation of UFP $C_{(s)}$ with $A_{(g)}$ and $B_{(g)}$ being the precursors.

$$
a A_{(g)}+b B_{(g)}=c C_{(s)}+d D_{(g)}
$$

SR can be derived in terms of the thermodynamic quantities:

$$
\begin{aligned}
& \mathrm{SR}=\left[\mathrm{P}_{\mathrm{A}}^{\mathrm{a}} \mathrm{P}_{\mathrm{B}}^{\mathrm{b}} / \mathrm{P}_{\mathrm{D}}^{\mathrm{d}}\right]_{\text {react }} /\left[\mathrm{P}_{\mathrm{A}}^{\mathrm{a}} \mathrm{P}_{\mathrm{B}}^{\mathrm{b}} / \mathrm{P}_{\mathrm{D}}^{\mathrm{d}}\right]_{\text {equil }} \\
& \mathrm{SR}=\mathrm{K}\left(\mathrm{P}_{\mathrm{A}}^{\mathrm{a}} \mathrm{P}_{\mathrm{B}}^{\mathrm{b}} / \mathrm{P}_{\mathrm{D}}^{\mathrm{d}}\right)_{\text {react }}
\end{aligned}
$$

Kato (48)

where $\mathrm{K}$ is the equilibrium constant for reaction (1). $\mathrm{K}$ is related to the homogeneous gas reaction UFP production. Kato (48) mentionned that a large $K$ should be related to high reaction rates. Plasma technology is very well adapted to provide the high temperature necessary to increase the reaction rate. Numerical analyses of the nucleation and growth of UFP have been proposed by Girshick et al. $(49,50)$, Proulx et al. (51), Bilodeau et al. (52), all found good agreement between their computed and experimental data.

\section{CONCLUSION}

The UFP production of $\mathrm{SiC}$ by the induction plasma technique has been reviewed with the emphasis on the various precursors used, and the different technological choices. As the formation of UFP in the plasma involves complex mechanisms, there is a need for an interdisciplinary approach, with researchers working in diagnostics and modelling, as well as materials specialists for the powder quality evaluation. From the economics point of view, when production of high purity, high specific area SiC powder is desired, metallic $\mathrm{Si}$, with a particle size smaller than $30 \mu \mathrm{m}$, is an attractive precursor, using methane as the carburizing agent, coinjected with the powder $\mathrm{Si}$ in an induction plasma. As the modelling of the thermodynamic and kinetic phenomena involved in the induction plasma reactor is progressed and it can satisfactorily describe some experimental data, the design of plasma reactors will benefit greatly from this knowledge, and in consequence, the operational scale-up of some of the reactors described in this text for industrial production can be achieved!

\section{ACKNOWLEDGEMENT}

The author would like to thank Dr Peter Lanigan for his contribution to the proofreading of this paper.

\section{REFERENCES}

\section{A. Kato. Ceramic Bul. 66, 4, 647-650 (1987)}

2. R.A. Andrievski. J. Mater. Sci. 29, 614-631 (1994).

3. G.P. Vissokov et al. J. Mater. Sci. 23, 2415-2418 (1988)

4. I. Stamenkovic. Mat. Chem. and Phys., 23, 389-407, (1989)

5. P.C. Kong and E. Pfender. Heat transfer in thermal plasma processing, ASME, New York, HTD, 161 (1991)

6. R.M. Young and E. Pfender. Plasma Chem. Plasma Process, 5, 1, 1-37 (1985)

7. B. Waldie. The Chem. Eng., 3, 92-96 (1972)

8. H. Anderson et al. Ceram. Bul., 68, 5, 996-1000 (1989)

9. P. Kong et al. Material Research Society Symposium Proceedings, 190, San Francisco, CA, April 17-19 (1990)

10. M.I. Boulos. J. of Ther. Spray Techn., 1, 33-40 (1992)

11. S.G. Sheshadri et al. Proceedings of the Silicon Carbide 87, 2, 215-226, Colombus, Ohio, edited by J.D. Cawley and C.E. Semler (1989)

12. H. Gleiter. Progr. Mater. Sci. 33, 223 (1989)

13. A. Kato et al. J. of Japan Soc., Powder and Powder Metall., 27, 1, $32-34$ (1980)

14. G.J. Vogt et al. Synthesis of Ultrafine Ceramic and Metallic Powders in a Thermal Argon RF Plasma, B-4-3 in Proc. of ISPC-7, Eindhoven, Netherlands (1985)

15. K. Kijima et al. Eighth International Symposium on Plasma Chemistry, Tokyo, Japan, 4, 2121-2126 (1987)

16. M. Suzuki et al. J. Jpn. Ceram. Soc., 99, 11, 1159-1162 (1991)

17. R. Mach et al. Key Eng. Mater., 89-91, $41-46$ (1994)

18. T. Inukai. J. of Japan Soc., Powder and Powder Metall., 27, 8, 249-251, (1980)

19. A. Mitsui and A. Kato. Yogyo Kyokaishi, 94, 5, 517 (1986) 
20. C.M. Hollabaugh et al. J. Mater. Sci., 18, 3190-3194 (1983)

21. T. Kameyama et al. J. Mater. Sci., 25, 1058-1065 (1990)

22. T. Yoshida et al. The preparation of Ultrafine Si3N4 Particles in a Hybrid Plasma, p.225 in Proc. of ISPC-6, Montreal, Canada (1983)

23. S.K. Lee et al. J. Amer. Ceram. Soc., 77, 6, 1655-1658 (1994)

24. British Titan Products Co. Neth.Appl. Patent 6, 601, 831, CA, 66, 5492 (1967)

25. W.E. Kuhn. J.of Electrochemical Soc., 110, 4, 298-306 (!(63

26. Y. Ando et al. Jpn. J. Appl. Phys., 19, 11, L693-L694 (1980)

27. P.C.Kong et al. Synthesis of Silicon Carbide in a Thermal Plasma, A-7-2, Proc. of ISPC-6, Montreal, Canada (1983)

28. P.C.Kong et al. $\beta$-SiC Synthesis in an Atmospheric Pressure Convection-Stabilized Arc, B-4-4, Proc. of ISPC-7, Eindhoven, Netherlands (1985)

29. Y. Inoue et al. J. Mater. Sci., 24, 3819-3823 (1989)

30. Y. Nariki et al. J. Mater. Sci., 25, 3101-3104 (1990)

31. K. Tanaka et al. J. Mater. Sci., 22, 2192-2198 (1987)

32. L. Stachowicz et al. Plasma Chem. and Plasma Process., 13, 3, 447-461 (1993)

33. J. Kondo and G. Saiki. Synthesis and Sintering of B-Doped SiC Powders by Plasma Arc Method, Poster 16-BP-86, Amer. Ceram. Soc. Annual Meeting, Chicago, Illinois (1986)

34. T.J. Carbone and B.R. Rossing. Poceedings of 2 nd Inter. Symposium on Ceram. Mater. and Components for Engines, 47-54, Luebeck-Travemuende, West Germany (1986)

35. H.R. Baumgartner and B.R. Rossing. Proceedings of the Silicon Carbide 87, 2, 3-16, Colombus, Ohio, edited by J.D. Cawley and C.E. Semler 1989)(1989)

36. P.H. Dundas. Induction plasma heating, measurements of gas concentrations, temperatures and stagnation heads in a binary plasma system, NASA contract Report, NASA CR-1527, Washington, DC (1970)

37. R.M. Barnes and S. Nikdel, Appl. Spectrosc., 29, 477-481 (1975)

38. M. Rahmane et al. Int. J. Heat Mass Transfer, 37,14, 2035-2046 (1994)

39. G. Soucy et al. Plasma Chem. and Plasma Process., 14, 1, 59-71 (1994)

40. G. Soucy et al. Plasma Chem. and Plasma Process., 14, 1, 43-58 (1994)

41. C.B. Laflamme. Synthèse de poudres ultafines de carbure de silicium dans un réacteur à plasma à courant continu, Thèse de doctorat, Université de Sherbrooke (1991)

42. Guo. Synthèse par plasma et frittage de poudres ultrafines de carbure de silicium, Thèse de doctorat, Université de Sherbrooke (1995)

43. J.E.McDonald. Amer. J. Phys, 30, 12, 870-877 (1962)

44. J.E.McDonald. Amer. J. Phys, 31, 2, 238-256 (1963)

45. F.F. Abraham. Homogeneous Nucleation Theory: the Pretransition Theory of Vapor Condensation, Academic Press, New York, p. 263 (1974)

46. G.S. Springer. Homogeneous Nucleation in Advances in Heat Transfer, Academic Press, New York, 14, $281-346(1978)$

47. S.L. Girshick et al. Amer. Sc. Tech., 13, 465-477 (1990)

48. A. Kato. Ceramic Powder Science Advances in Ceramics 21, Amer.Ceram.Soc. (1987)

49. S.L. Girshick et al. Plasma Chem. and Plasma Process., 8, 145-147 (1988)

50. S.L. Girshick et al. Plasma Chem. and Plasma Process., 9, 355-369 (1989)

51. P. Proulx et J.F. Bilodeau. Plasma Chem. Plasma Process., 11, 3, $371-385$ (1991)

52. J.-F. Bilodeau et al. Comptes-rendus, 11eme Symposium international sur la chimie des plasmas, 1, 356-361, Loughborough, Grande-Bretagne 